\title{
CURRENT STATUS OF ENDOCRINE THERAPY IN LOCALIZED PROSTATE CANCER: CURE HAS BECOMEASTRONG POSSIBILITY
}

\author{
FERNAND LABRIE \\ Oncology and Molecular Endocrinology Research Center, Laval University Medical Center (CHUL), \\ Quebec City, Quebec, Canada
}

\begin{abstract}
It is clear that all available means should be taken to diagnose prostate cancer early and to use efficient therapy immediately in order to prevent prostate cancer from migrating to the bones where treatment becomes extremely difficult and cure or even long-term control of the disease is an exception. The only means of preventing prostate cancer from migrating to the bones and becoming incurable is efficient treatment at the localized stage of the disease. In fact, since radical prostatectomy, radiotherapy and brachytherapy can achieve cure in about $50 \%$ of cases, these approaches are all equally valid choices as first treatment of localized prostate cancer. However, in view of the current knowledge and available data, nowadays, androgen blockade should also be considered as first line treatment.

While showing the high efficacy of hormonal therapy in localized prostate cancer, present knowledge clearly indicate that long-term treatment with the best available hormonal drugs, somewhat similar to the 5 years of Tamoxifen in breast cancer, is required for optimal control of prostate cancer. It is also clear from the data analyzed that combined androgen blockage alone could well be an efficient therapy of localized prostate cancer while it has already been recognized as the best therapy for metastatic disease.

This paper presents and discusses the current knowledge available on the use and results of endocrine therapy in localized prostate cancer.
\end{abstract}

Key words: prostatic neoplasms; therapy; androgens; androgen blockade; LHRH receptor; antiandrogens; screening

Int Braz J Urol. 2004; 30: 3-11

\section{INTRODUCTION}

Prostate cancer is the most frequently diagnosed cancer and the second cause of cancer death in men in North America (1). In fact, one out of eight men will be diagnosed with prostate cancer during his lifetime. At the present rate, prostate cancer will kill more than 3,000,000 men among the male population presently living in the United States. In fact, prostate cancer kills more than 200,000 men annually worldwide. The medical and social conse- quences of this disease are comparable to those of breast cancer in women.

\section{PROSTATE CANCER DEATHS ARE DECREASING}

Death rates from prostate cancer have dropped by $17 \%$ in the United States since 1994 (Figure-1). This decrease in prostate cancer death coincides with the routine use of the prostate specific antigen (PSA) test. 


\section{Prostate cancer deaths}

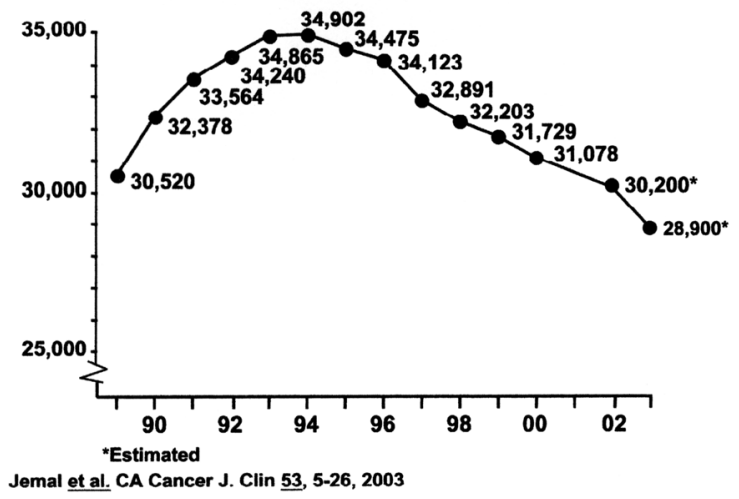

Figure 1 - Prostate cancer deaths in the United States since 1989. Note that deaths have dropped by $17 \%$ since 1994.

\section{SCREENING PICKS UP THE DISEASE EARLY, AT A TIME WHEN CURE IS A POS- SIBILITY}

Despite the progress achieved in the treatment of advanced or metastatic prostate cancer using LHRH agonists $(2,3)$ and especially combined androgen blockade (4-11), it is well recognized that the only possibility of a significant reduction in prostate cancer mortality is the treatment of localized disease (12). It is reasonable to suggest that the observed decrease in deaths from prostate cancer is due to earlier diagnosis with serum PSA (13) and transrectal ultrasound of the prostate (14) coupled with improved treatment of localized disease by surgery, radiotherapy, brachytherapy, and endocrine therapy $(12,15-18)$.

However, since prostate cancer almost invariably develops insidiously without signs or symptoms until the non curable stage of bone metastases is reached, early treatment cannot be achieved without efficient screening in asymptomatic men. In the first prospective and randomized study of screening for prostate cancer, namely the Laval University Prostate Cancer Screening Program started in 1988 in Quebec City among 46,486 men aged 45 to 80 years, it has been found that screening permits to diagnose $99 \%$ of prostate cancers at a clinically localized or potentially curable stage. Screening practically eliminates the diagnosis of metastatic and non curable disease $(13,19)$.

As clearly indicated in our previous reports $(13,19)$, the most cost-effective strategy for early diagnosis of prostate cancer is measurement of serum PSA as first line or as a prescreening test in order to identify the men who are at a higher risk of prostate cancer. The same conclusion of the high efficacy of the PSA has been reached in 2 other large scale screening studies (20-22). A similar conclusion has been reached by Hugosson et al. (23) who wrote: "PSA seems to be excellent as a prescreening test to identify the population at risk and which needs further evaluation $(24,25)$ ". Screening provides a lead time of at least 6 years and permits "early treatment". In our screening study, digital rectal examination was routinely done at first visit but not at follow-up visits while transrectal ultrasound was performed if PSA and/or digital rectal examination were abnormal. With this screening approach used at more than 60,000 follow-up visits, $99 \%$ of cancers were diagnosed at a localized and therefore potentially curable stage. Such a strategy has resulted in a $62 \%$ reduction of prostate cancer death at 11 years of follow-up (Figure-2).

\section{MAJOR ROLE OF ANDROGEN BLOCKADE}

\section{A - Localized Disease (monotherapy, medical or surgical castration alone): Major Im- provement of Survival}

Our research group at the Laval University Medical Research Center in Quebec City has discovered that medical castration can be easily and very efficiently achieved in men using the well tolerated luteinizing hormone-releasing hormone (LHRH) agonists $(2,4,26,27)$. This novel approach has eliminated the previous limitations associated with blockade of testicular androgens since the pioneering work of Huggins et al., 1941 (28). These limitations are the psychological problems of surgical castration and the serious and even life-threatening side effects of high doses of estrogens on the cardiovascular system (29-31). In fact, the availabil- 
(1100 000 men - year)

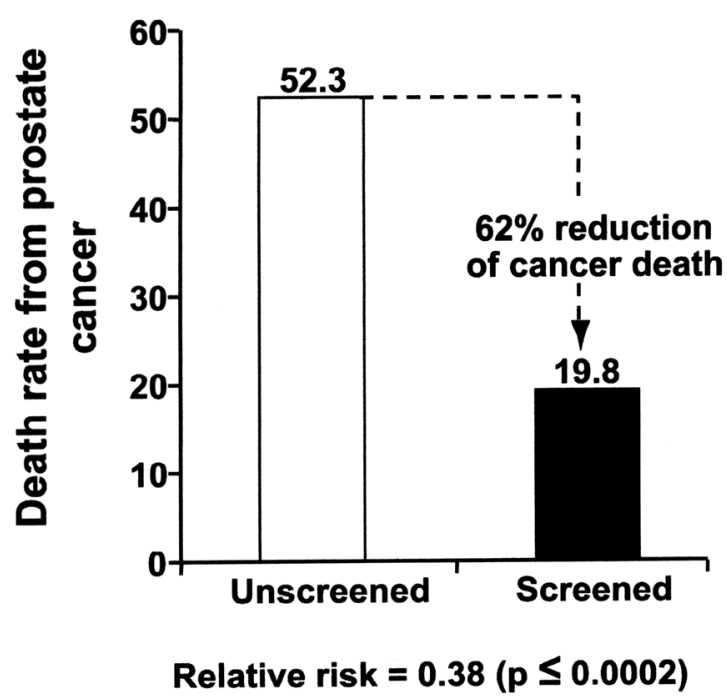

Figure 2-Graphic demonstrating that PSA screening and consequently early diagnosis of prostate cancer at a localized stage resulted in a $62 \%$ reduction of prostate cancer death at 11 years of follow-up.

ity of the well tolerated medical castration achieved with LHRH agonists (2) has opened the way to a much more acceptable treatment of prostate cancer, especially for localized disease where well tolerated therapies are particularly important for long term administration.

Medical castration with an LHRH agonist is equivalent to orchiectomy for prostate cancer therapy (11). In fact, in 11 trials where an LHRH agonist was used and in 17 trials where orchiectomy was used, no difference was seen on the response or survival rate (PCTCG, 2000) (11). In fact, only LHRH agonists could permit studies in localized disease. Although equally efficient, orchiectomy is very difficult to accept in the absence of symptoms and signs of cancer.

The major source of controversy concerning early diagnosis and treatment of prostate cancer has been that, until recently, no prospective and randomized trial had shown statistically significant benefits on survival of treatment of localized prostate cancer $(32,33)$. Such an absence of studies has been erroneously interpreted as being equivalent to the presence of negative data while, in fact, negative data have never been obtained concerning the effect of androgen blockade in localized prostate cancer. On the contrary, 6 prospective randomized trials have recently demonstrated that an important prolongation of life was obtained in localized prostate cancer treated with androgen blockade (34-39). Quite remarkably, in various studies, the improved cancer-specific survival ranges between $37 \%$ and $81 \%$ at 5 years of follow-up in patients with localized disease who received androgen blockade compared with controls not immediately treated with androgen blockade. In fact, the first prospective and randomized studies that have shown statistically significant benefits on survival in localized or locally advanced prostate cancer are those using androgen blockade.

It is clear that the lifesaving benefits of androgen blockade in prostate cancer have been largely underestimated. In fact, the results obtained are quite remarkable and are similar or even better than the benefits observed for Tamoxifen in breast cancer.

\section{B - Localized Disease - Combined Androgen Blockade (castration plus a pure antiandrogen): Strong Possibility of a Cure}

We can do better than medical or surgical castration in terms of androgen blockade and thus obtain superior results.

Following the discovery of the castration effect of LHRH agonists (2), the next most important advance made in our understanding of the biology and endocrinology of prostate cancer and its impact on cancer treatment is the observation that humans and some other primates are unique among animal species in having adrenals that secrete large amounts of the inactive precursor steroids dehydroepiandrosterone (DHEA), its sulfate DHEA-S, and some androstenedione (4-dione), which are converted into potent androgens in a large series of peripheral tissues, including the prostate (Figure-3). In fact, the plasma concentration of DHEA-S secreted by the adrenals in adult men is 100 to 500 times higher than that of testosterone (40), the main secretory product of the testicles. Such high circulating levels of DHEA-S (and also DHEA) provide high amounts of the prehormones or precur- 


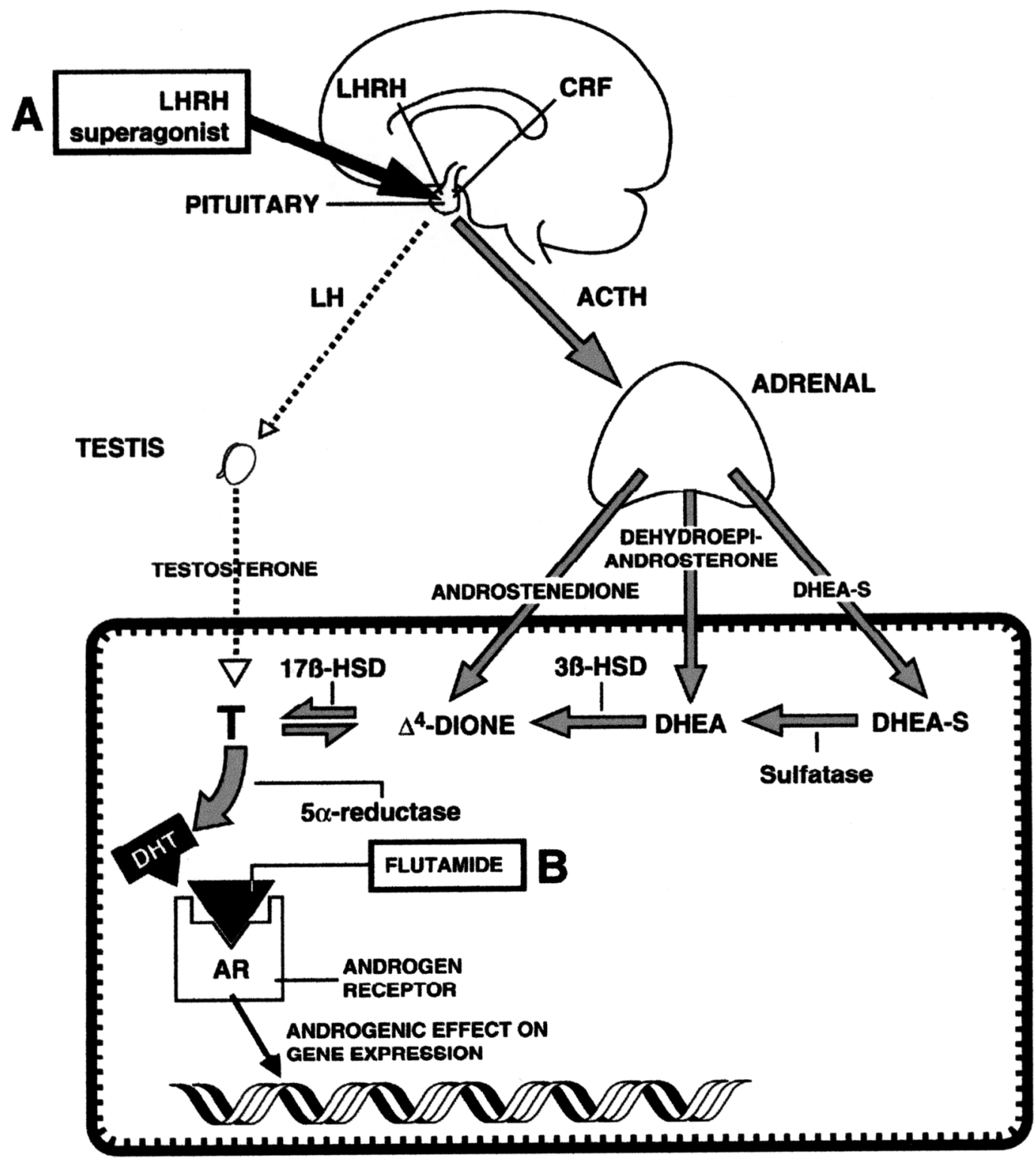

PROSTATIC CELL

Figure 3 - Intracrine activity of the human prostate or biosynthetic steps involved in the formation of the active androgen dihydrotestosterone (DHT) from testicular testosterone as well as from the inactive adrenal precursors DHEA, DHEA-sulfate (DHEA$S)$, and 4-dione in human prostatic tissue. 17?-hydroxysteroid dehydrogenase; $3 ?-H S D=3 ?$-hydroxysteroid dehydrogenase/? ${ }^{5}-?^{4}-$ isomerase. The widths of the arrows indicate the relative importance of the sources of DHT in the human prostate: $60 \%$ originating from the testes and 40\% from the adrenals in 65-year-old men. The testis secretes testosterone $(T)$ which is transformed into the more potent androgen DHT by 5? -reductase in the prostate. Instead of secreting T or DHT directly, the adrenal secretes very large amounts of DHEA and DHEA-sulfate (DHEA-S), which are transported in the blood to the prostate and other peripheral tissues. These inactive precursors are then transformed locally into the active androgens $T$ and DHT. The enzymatic complexes DHEA sulfatase, 3?-HSD, 17?-HSD and 5? -reductase are all present in the prostatic cells, thus providing 40\% of total DHT in this tissue. (From Labrie F: Androgen blockade in prostate cancer in 2002: major benefits on survival in localized disease. Mol Cell Endocrinol. 2002; 198: 7787.) 
sors required for conversion into active androgens in the prostate as well as in other peripheral intracrine tissues.

The local synthesis of active steroids in peripheral target tissues has been called intracrinology $(41,42)$. The active androgens made locally in the prostate exert their action by interacting with the androgen receptor in the same cells where their synthesis takes place without being released in the extracellular environment or the general circulation. Contrary to the previous belief that the testes are responsible for $90-95 \%$ of total androgen production in men (as suggested by the decrease in serum testosterone after castration), it is now well demonstrated that the prostatic tissue efficiently transforms the inactive steroid precursors DHEA-S, DHEA, and 4-dione into the active androgens testosterone and DHT locally in peripheral tissues without significant release of the active androgen in the circulation. In fact, the prostate makes its own androgens at a level comparable to the androgens of testicular origin.

The results obtained in a large series of clinical trials in patients with advanced prostate cancer have demonstrated that combined androgen blockade compared to castration alone has the following advantages: 1) more complete and partial responses, 2) improved control of metastatic pain, 3) longer disease-free survival, and 4) longer survival.

However, further improvement of the treatment of metastatic disease with the only efficient approach available, namely androgen blockade, is very difficult. By far the best possibility of improvement for the prostate cancer patient is treatment of localized disease. In fact, in analogy with the treatment of all other types of cancers, the beneficial effects are much greater when the same treatment is applied at an earlier stage of the disease.

With long-term treatment of localized prostate cancer, the evidence obtained even indicates that long term control or cure of the disease can be obtained in the majority of patients (18). While almost all studies performed so far in localized prostate cancer have used monotherapy (medical or surgical castration) (34-39), there are good reasons to believe that even better results will be obtained with combined androgen blockade - CAB . Since we already had obtained evidence for the high efficacy of long term and continuous CAB in localized prostate cancer (45), it was felt important to examine the long term outcome of these patients as assessed by biochemical failure or PSA rise following cessation of continuous CAB previously administered for periods up to 11.3 years.

The effect of $\mathrm{CAB}$ on long-term control or possible cure of prostate cancer was thus evaluated by the absence of biochemical failure or the absence of PSA rise for at least 5 years after cessation of continuous treatment. A total of 57 patients with localized or locally advanced disease received $\mathrm{CAB}$ for periods ranging from 1 to 11 years. With a minimum of 5 years of follow-up after cessation of longterm $\mathrm{CAB}$, only 2 PSA rises occurred among 20 patients with Stage T2-T3 cancer who stopped treatment after continuous $\mathrm{CAB}$ for more than 6.5 years, for a nonfailure rate of $90 \%$ (Figure-4). On the other hand, for the 11 patients who had received $\mathrm{CAB}$ for 3.5 to 6.5 years, the nonfailure rate was only $36 \%$. The serum PSA increased within 1 year in all 11 patients with Stage B2/T2 treated with $\mathrm{CAB}$ for only 1 year, thus indicating that active cancer remained present after short-term androgen blockade despite undetectable PSA levels. Most importantly, in all patients who had biochemical failure after stopping $\mathrm{CAB}$, serum PSA rapidly decreased again to undetectable levels when $\mathrm{CAB}$ was restarted, PSA remained at such low levels afterward. Of these patients, only 1 patient had died of prostate cancer at last follow-up (18).

With the knowledge of the above-described data, it seems reasonable to suggest that the minimal duration of continuous $\mathrm{CAB}$ in localized prostate cancer should be 6 years, thus providing an approximately $50 \%$ probability of long-term or possible cure of the cancer. With longer duration of $\mathrm{CAB}$, the probability increases to about $90 \%$ at 8 10 years of treatment. The present data indicate that possible cure of the disease can be obtained in the majority of patients with localized prostate cancer treated continuously with $\mathrm{CAB}$ for more than 6 years, thus raising hopes for the successful treatment of patients who fail after surgery, radiotherapy 
Effect of duration of continuous CAB on the \% of probable cure of localized prostate cancer

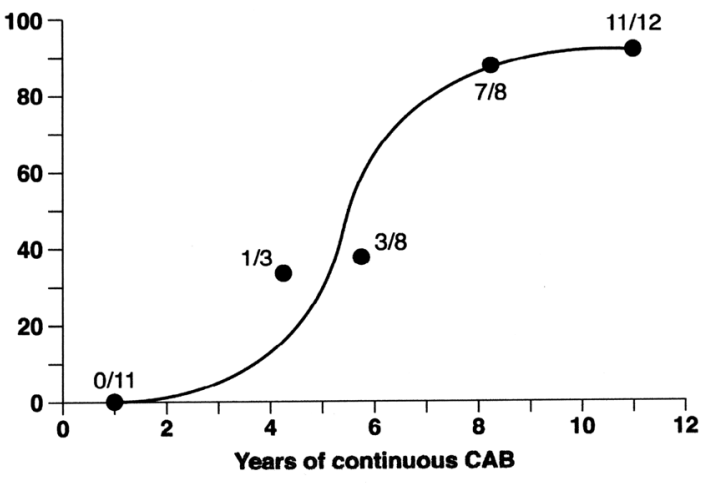

Figure 4 - Effect of duration of treatment of localized prostate cancer with continuous combined androgen ablation $(C A B)$ on the probability of long term control or "cure of the disease" illustrated by no recurrence of PSA rise for at least 5 years after cessation of $C A B$. The point at 4.75 years of treatment (33\%) refers to the 3 patients treated with $C A B$ for 3.5-5.0 years and followed for at least 5 years, while the point at 5.75 years refers to the 8 patients treated continuously with $C A B$ for 5.0-6.5 years before cessation of treatment. The point at 8.25 years refers to the 8 patients treated continuously for 6.5-9.0 years while the point at 11 years refers to the 13 patients treated for 10-11.7 years with continuous $C A B$ before stopping treatment. All patients were followed for at least 5 years after cessation of continuous CAB or until PSA rise. Only 1 patient has died from prostate cancer while 18 have died from other causes. (From Labrie F, Candas B, Gomez JL, Cusan L: Can combined androgen blockade provide long-term control or possible cure of localized prostate cancer? Urology. 2002; 60: 115-9).

or brachytherapy where no or minimally effective alternative therapeutic approach exists. Such data clearly indicate the interest of a large scale randomized study comparing monotherapy versus $\mathrm{CAB}$ in the group of patients showing biochemical failure after first therapy with a curative intent. Care should be taken, however, to start treatment early after the rise of serum PSA in order to use androgen blockade at its maximal level of efficacy, namely when the cancer is still localized to the prostate or the prostatic area, before metastases reach the bones when cure becomes an exception.

\section{C - Metastatic Disease: Prolongation of Life with Combined Androgen Blockade}

The first treatment shown to prolong life in prostate cancer is the combination of an LHRH ago- nist (blocker of androgen secretion by the testes; (2) associated with a pure antiandrogen such as flutamide, nilutamide or bicalutamide (at the proper dose, namely at least $150 \mathrm{mg}$ daily). When associated with castration which eliminates the androgens of testicular origin, these compounds block the action of the androgens produced locally in the prostate $(4,5,8,10,40,46)$.

An interesting observation is that the first demonstration of the benefits of $\mathrm{CAB}$ have been obtained in the most difficult group of patients to treat, namely those suffering from metastatic or advanced disease. Although the clinical data to be obtained should be similar for bicalutamide, the 2 antiandrogens flutamide and nilutamide have both been shown, as mentioned above in prospective and randomized studies, to prolong life, to increase the number of complete and partial responses, to delay progression, and to provide better pain control (thus improving quality of life) in metastatic prostate cancer when added to surgical or medical castration compared with castration alone $(5-11,46,47)$. In the first large scale randomized study, patients who were treated with flutamide and the LHRH agonist Lupron lived, on average, 7.3 months longer than those who received Lupron plus placebo (5).

Analysis of all the studies performed with flutamide and nilutamide associated with medical or surgical castration compared with castration plus placebo shows that overall survival is increased by an average of 3-6 months $(5-11,46,47)$. Since about 50\% of patients in that age group die from causes other than prostate cancer, this 3-6 month difference in overall survival translates into an average of 6-12 months of life gained when cancer-specific survival is analyzed. These additional months, or sometimes, years of life can be obtained by simply adding a pure antiandrogen (flutamide, nilutamide or bicalutamide at a proper dose) to castration. These data demonstrate the particularly high level of sensitivity of prostate cancer to androgen deprivation, considering that such statistically significant benefits on survival are obtained, even at the very advanced stage of metastatic disease.

Bennett at al. (8) have performed a meta-analysis of all peer-reviewed published randomized controlled trials comparing treatment with flutamide in association with medical (LHRH agonist) or surgical 
castration versus castration alone in advanced prostate cancer. Nine studies with 4,128 patients were included in the analysis, which demonstrated a statistically significant $10 \%$ improvement in overall survival with the combination therapy using flutamide compared with castration alone. Similar benefits have been obtained in favor of flutamide plus castration versus castration alone in the metaanalysis of Bennett et al. (8) and that of the Prostate Cancer Trialist's Collaborative Group (PTCTG). As mentioned above and predicted (48), the difference has also become statistically significant in the most recent PCTCG analysis (11).

With the clinical data summarized above, the controversy concerning $\mathrm{CAB}$ should be part of history and the addition of a pure antiandrogen should be recognized by all as providing an average advantage of 3-6 months of life in metastatic disease at a time when no alternative treatment even exists. When considering cancer-specific survival, the data show that 6-12 months of life are added by simply adding a pure antiandrogen to medical or surgical castration $(6,8,10,11,49)$.

\section{CONCLUSION}

While showing the high efficacy of hormonal therapy in localized prostate cancer, the present data clearly indicate that long-term treatment with the best available drugs, somewhat similar to the 5 years of Tamoxifen in breast cancer, is required for optimal control of prostate cancer. Great caution should be taken, however, when using serum PSA as surrogate marker. In fact, serum PSA rapidly and easily decreases to undetectable levels under androgen blockade although the cancer remains present for much longer periods of time, usually for many years as demonstrated in our recent study (18). For this reason, intermittent therapy should not be recommended outside prospective and randomized clinical trials.

With the present knowledge, it is clear that all available means should be taken to diagnose prostate cancer early and to use efficient therapy immediately in order to prevent prostate cancer from migrating to the bones where treatment becomes extremely difficult and cure or even long-term control of the disease is an exception. The only means of preventing prostate cancer from migrating to the bones and becoming incurable is efficient treatment at the localized stage of the disease. In fact, since radical prostatectomy, radiotherapy and brachytherapy (implantation of radioactive seeds in the prostate) can achieve cure in about $50 \%$ of cases, these approaches are all equally valid choices as first treatment of localized prostate cancer. Androgen blockade should also be considered as first line treatment. The most important, however, is to follow closely serum PSA after surgery, radiotherapy and brachytherapy and to start $\mathrm{CAB}$ as soon as signs of recurrence of the cancer appear. It is also clear from the data summarized above that $\mathrm{CAB}$ alone could well be the most efficient therapy of localized prostate cancer while it has already been recognized as the best therapy for metastatic disease.

Clearly, the rational use of the presently available diagnostic and therapeutic approaches could decrease prostate cancer death by at least $50 \%(13,37)$. As an example, between 1991 and 1999, the death rate form prostate cancer has decreased by $38 \%$ in Québec City and its metropolitan area (50) while the death rate has decreased by $62 \%$ in the group of men who have been screened (Figure-2).

\section{REFERENCES}

1. Jemal A, Murray T, Samuels A, Ghafoor A, Ward E, Thun MJ: Cancer statistics 2003. CA Cancer J Clin. 2003; 53: 5-26.

2. Labrie F, Bélanger A, Cusan L, Séguin C, Pelletier G, Kelly PA, et al.: Antifertility effects of LHRH agonists in the male. J. Androl. 1980; 1: 209-28.

3. Labrie F, Bélanger A, Cusan L, Simard J, Luu-The V, Labrie C, et al.: History of LHRH agonists and combination therapy in prostate cancer. Endocrine-Related Cancer. 1996; 3: 243-78.

4. Labrie F, Dupont A, Bélanger A, Cusan L, Lacourcière Y, Monfette G, et al.: New hormonal therapy in prostatic carcinoma: combined treatment with an LHRH agonist and an antiandrogen. Clin. Invest. Med. 1982; 5: $267-75$

5. Crawford ED, Eisenberger MA, McLeod DG, Spaulding JT, Benson R, Dorr FA, et al.: A controlled trial of leuprolide with and without flutamide in prostatic carcinoma. N. Engl. J. Med. 1989; 321: 419-24.

6. Dijkman GA, Janknegt RA, Dereijke TM, Debruyne FMJ: Long-term efficacy and safety of nilutamide plus castration in advanced prostate-cancer, and the signifi- 
cance of early prostate specific antigen normalization. J. Urol. 1997; 158: 160-3.

7. Denis LJ, Keuppens F, Smith PH, Whelan P, Carneiro de Moura JL, Newling D, et al.: Maximal androgen blockade: final analysis of EORTC Phase III trial 30853. Eur Urol. 1998; 33: 144-51.

8. Bennett CL, Tosteson TD, Schmitt B, Weinberg PD, Ernstoff MS, Ross SD: Maximum androgen-blockade with medical or surgical castration in advanced prostate cancer: a meta-analysis of nine published randomized controlled trials and 4128 patients using Flutamide. Prost Cancer Prost Dis. 1999; 2: 4-8.

9. Caubet JF, Tosteson TD, Dong EW, Naylon EM, Whiting GW, Ernstoff MS, et al.: Maximum androgen blockade in advanced prostate cancer: a meta-analysis of published randomized controlled trials using nonsteroidal antiandrogens. Urology. 1997; 49: 71-8.

10. Schmitt B, Wilt TJ, Schellhammer PF, DeMasi V, Sartor $\mathrm{O}$, Crawford ED, et al.: Combined androgen blockade with nonsteroidal antiandrogens for advanced prostate cancer: a systematic review. Urology. 2001; 57: 727-32.

11. Prostate Cancer Triallists' Collaborative Group: Maximum androgen blockade in advanced prostate cancer: an overview of the randomised trials. Lancet. 2000; 355: 1491-8.

12. Labrie F, Cusan L, Gomez JL, Diamond P, Bélanger A: Long-term neoadjuvant and adjuvant combined androgen blockade is needed for efficacy of treatment in localized prostate cancer. Mol Urol. 1997; 1: 253-61.

13. Labrie F, Candas B, Cusan L, Gomez JL, Diamond P, Suburu R, et al.: Diagnosis of advanced or noncurable prostate cancer can be practically eliminated by prostate-specific antigen. Urology. 1996; 47: 212-7.

14. Lee F, Torp-Pedersen ST, Siders DB, Littrup PJ, McLeary RD: Transrectal ultrasound in the diagnosis and staging of prostatic carcinoma. Radiology. 1989; 170: 609-15.

15. Labrie F, Cusan L, Gomez JL, Diamond P, Suburu R, Lemay M, et al.: Downstaging of early stage prostate cancer before radical prostatectomy: the first randomized trial of neoadjuvant combination therapy with Flutamide and a luteinizing hormone-releasing hormone agonist. Urology. 1994; 44: 29-37.

16. Laverdiere J, Gomez JL, Cusan L, Suburu R, Diamond $\mathrm{P}$, Lemay M, et al.: Beneficial effect of combination therapy administered prior and following external beam radiation therapy in localized prostate cancer. Int. J. Radiat. Oncol. Biol. Phys. 1997; 37: 247-52.

17. Labrie F: Androgen blockade in prostate cancer in 2002 : major benefits on survival in localized disease. Mol Cell Endocrinol. 2002; 198: 77-87.
18. Labrie F, Candas B, Gomez JL, Cusan L: Can combined androgen blockade provide long-term control or possible cure of localized prostate cancer? Urology. 2002; 60: 115-9.

19. Candas B, Cusan L, Gomez J-L, Diamond P, Suburu RE, et al.: Evaluation of prostatic specific antigen and digital rectal examination as screening tests for prostate cancer. Prostate. 2000; 45: 19-35.

20. Schröder FH, Maas PVD, Beemsterboer P, Kruger AB, Hoedemaeker R, Rietbergen J: Evaluation of the digital rectal examination as a screening test for prostate cancer. J Natl Cancer Inst. 1998; 90: 1817-1823.

21. Makinen T, Tammela TL, Hakama M, Stenman UH, Rannikko S, Aro J, et al.: Prostate cancer screening within a prostate specific antigen range of 3 to $3.9 \mathrm{ng} . /$ $\mathrm{ml} .:$ a comparison of digital rectal examination and free prostate specific antigen as supplemental screening tests. J Urol. 2001; 166: 1339-42.

22. Schröder FH, Roobol-Bouts M, Vis AN, Kwast TVD, Kranse R: Prostate-specific antigen-based early detection of prostate cancer-validation of screening without rectal examination. Urology. 2001; 57: 83-90.

23. Hugosson J, Aus G, Becker C, Carlsson S, Eriksson H, Lilja H, et al.: Would prostate cancer detected by screening with prostate-specific antigen develop into clinical cancer if left undiagnosed? A comparison of two population-based studies in Sweden. BJU Int. 2000: 85: 1078-84.

24. Bangma CH, Kranse R, Blijenberg BG, Schroder FH: The value of screening tests in the detection of prostate cancer. Part I: Results of a retrospective evaluation of 1726 men. Urology. 1995; 46: 773-8.

25. Lodding P, Aus G, Bergdahl S, Frosing R, Lilja H, Pihl $\mathrm{CG}$, et al.: Characteristics of screening detected prostate cancer in men 50 to 66 years old with 3 to $4 \mathrm{ng} . / \mathrm{ml}$. prostate specific antigen. J Urol. 1998; 159: 899-903.

26. Faure N, Labrie F, Lemay A, Bélanger A, Gourdeau Y, Laroche B, et al.: Inhibition of serum androgen levels by chronic intranasal and subcutaneous administration of a potent luteinizing hormone-releasing hormone (GNRH) agonist in adult men. Fertil Steril. 1982; 37: 416-24.

27. Tolis G, Ackman D, Stellos A, Mehta A, Labrie F, Fazekas ATA, et al.: Tumor growth inhibition in patients with prostatic carcinoma treated with LHRH agonists. Proc Natl Acad Sci. 1982; 79: 1658-62.

28. Huggins C, Hodges CV: Studies of prostatic cancer. I. Effect of castration, estrogen and androgen injections on serum phosphatases in metastatic carcinoma of the prostate. Cancer Res. 1941; 1: 293-307.

29. VACURG: Treatment and survival of patients with can- 
cer of the prostate. Surg Gynecol Obstet. 1967; 124: 1011-7.

30. Robinson MR, Thomas BS: Effect of hormone therapy on plasma testosterone levels in prostatic cancer. $\mathrm{Br}$ Med J 1971; 4: 391-4.

31. Peeling WB: Phase III studies to compare goserelin (Zoladex) with orchiectomy and with diethylstilbestrol in treatment of prostatic carcinoma. Urology. 1989; 33: 45-52.

32. Kolata G: Prostate cancer consensus hampered by lack of data. Science. 1987; 236: 1626-7.

33. Middleton RG, Thompson IM, Austenfeld MS, Cooner WH, Correa RJ, Gibbons RP, et al.: Prostate Cancer Clinical Guidelines Panel Summary report on the management of clinically localized prostate cancer. The American Urological Association. J Urol. 1995; 154: 2144-8.

34. Bolla M, Gonzalez D, Warde P, Dubois JB, Mirimanoff RO, Storme G, et al.: Improved survival in patients with locally advanced prostate cancer treated with radiotherapy and goserelin. N Engl J Med. 1997; 337: 295-300.

35. Pilepich MV, Caplan R, Byhardt RW, Lawton CA, Gallagher MJ, Mesic JB, et al.: Phase III trial of androgen suppression using Goserelin in unfavorable prognosis carcinoma of the prostate treated with definitive radiotherapy: report of Radiation Therapy Oncology Group protocol 85-31. J Clin Oncol. 1997; 15: 1013-21.

36. Granfors T, Modig H, Damber JE, Tomic R: Combined orchiectomy and external radiotherapy versus radiotherapy alone for nonmetastatic prostate cancer with or without pelvic lymph node involvement: a prospective randomized study. J Urol. 1998; 159: 2030-4.

37. Labrie F, Candas B, Dupont A, Cusan L, Gomez JL, Suburu RE, et al.: Screening decreases prostate cancer death: first analysis of the 1988 Quebec prospective randomized controlled trial. Prostate. 1999; 38: 83-91.

38. Messing EM, Manola J, Sarosdy M, Wilding G, Crawford ED, Trump D: Immediate hormonal therapy compared with observation after radical prostatectomy and pelvic lymphadenectomy in men with node-positive prostate cancer. N Engl J Med. 1999; 341: 1781-8.

39. Hanks GE, Lu J, Machtay M, Venkatesan V, Pinover W, Byhardt R, et al.: RTOG Protocol 92-02: A Phase III trial of the use of long term androgen suppression following neoadjuvant hormonal cytoreduction and radiotherapy in locally advanced carcinoma of the prostate. 36th Annual Meeting of the American Society of Clinical Oncology. 2000. New Orleans, LA, USA.

40. Labrie F, Dupont A, Bélanger A: Complete Androgen Blockade for the Treatment of Prostate Cancer. In: de
Vita VT, Hellman S, Rosenberg SA (eds.), Important Advances in Oncology. Philadelphia, JB Lippincott. 1985; pp. 193-217.

41. Labrie C, Bélanger A, Labrie F: Androgenic activity of dehydroepiandrosterone and androstenedione in the rat ventral prostate. Endocrinology. 1988; 123: 1412-7.

42. Labrie F: Intracrinology. Mol Cell Endocrinol. 1991; 78: C113-C8.

43. Labrie F: Prostate Cancer and Combined Androgen Blockade at All Stages of Disease. In: Khayat D, Hortobagyi GN (eds.), Progress in Anti-Cancer Chemotherapy. France, Springer. 2000; pp. 171-187.

44. Labrie F: Screening and early hormonal treatment of prostate cancer are accumulating strong evidence and support. Prostate. 2000; 43: 215-22.

45. Labrie F, Cusan L, Gomez JL, Belanger A, Candas B: Long-term combined androgen blockade alone for localized prostate cancer. Mol Urol. 1999; 3: 217-25.

46. Denis L, Carneiro de Moura J, Bono A, Sylvester R, Whelan P, Newling D, et al.: Goserelin acetate and flutamide vs bilateral orchiectomy: a phase III EORTC trial (30853). EORTC GU Group and EORTC Data Center. Urology. 1993; 42: 119-29.

47. Janknegt RA, Abbou CC, Bartoletti R, Bernstein-Hahn L, Bracken B, Brisset JM, et al.: Orchiectomy and Nilutamide or placebo as treatment of metastatic prostatic cancer in a multinational double-blind randomized trial. J Urol. 1993; 149: 77-83.

48. Labrie F, Crawford D: Anti-androgens in treatment of prostate cancer. Lancet. 1995; 346: 1030-1.

49. Brawer MK, Crawford ED, Labrie F, Mendoza-Valdez A, Miller PD, Petrylak DP: Advanced disease. Reviews in Urology. (in press)

50. Candas B, Labrie F: Unequal decrease of prostate cancer specific death rates through the Province of Quebec between 1991 and 1999. 14th Int. Symposium J. Steroid Biochem. Mol. Biol. 2000. Québec, Canada.

Received: December 5, 2003 Accepted: January 8, 2004

\author{
$\overline{\text { Correspondence address: }}$ \\ Dr. Fernand Labrie \\ Oncology and Molecular Endocrinology Research Center \\ Laval University Medical Center (CHUL) \\ 2705 Laurier Boulevard \\ Quebec City, Quebec, G1V 4G2, Canada \\ Fax: + 418 654-2735 \\ E-mail: fernand.labrie@crchul.ulaval.ca
}

